\title{
Major Suffers Sudden Cardiac Death After Annual Physical Ability Test - Kentucky
}

\section{Executive Summary}

On October 30, 2014, a 60-year-old male career Major underwent his fire department's annual medical evaluation and physical ability test (PAT). The PAT consisted of 10 timed maneuvers while wearing full turnout gear and self-contained breathing apparatus (SCBA). The Major completed all 10 maneuvers over 25 minutes without incident or complaint. On his way home, the Major stopped at an abandoned gas station and called 911 on his cell phone at 1058 hours. After talking with the 911 operator for a few seconds, the Major hung up. The 911 operator called back, but the Major stated he did not need assistance. About 10 minutes later the Major called a crew member to discuss a project. During that conversation the crew member told the Major that he did not sound well; the Major responded that he had just completed his annual medical/physical evaluation and there was no problem.

When the Major did not return home that evening (about 10 hours later), his family traced his cell phone and located him at the gas station. Fire department and ambulance paramedics responded and found him deceased for quite some time (cold body and rigor mortis). He was declared dead at the scene. The death certificate and the autopsy, completed by the county medical examiner, listed "hypertensive and atherosclerotic cardiovascular disease" as the cause of death with "obesity" as a contributing factor. The NIOSH investigators concluded that the Major's sudden cardiac death was probably due to a primary arrhythmia or a heart attack, precipitated by the physical stress of the physical ability test.

\section{Key Recommendations}

- Perform symptom-limiting exercise stress tests (ESTs) on fire fighters at increased risk for coronary heart disease (CHD) and sudden cardiac events

- Perform ESTs only on fire fighters at increased risk for CHD and sudden cardiac events

- Ensure that fire fighters are cleared for duty by a physician knowledgeable about the physical demands of fire fighting, the personal protective equipment used by fire fighters, and the components of National Fire Protection Association (NFPA) standard 1582

- Phase in a mandatory comprehensive wellness and fitness program for fire fighters. 


\section{Major Suffers Sudden Cardiac Death After Annual Physical Ability Test - Kentucky}

The National Institute for Occupational Safety and Health (NIOSH), an institute within the Centers for Disease Control and Prevention (CDC), is the federal agency responsible for conducting research and making recommendations for the prevention of work-related injury and illness. In 1998, Congress appropriated funds to NIOSH to conduct a fire fighter initiative that resulted in the NIOSH "Fire Fighter Fatality Investigation and Prevention Program" which examines line-of-duty-deaths or on duty deaths of fire fighters to assist fire departments, fire fighters, the fire service and others to prevent similar fire fighter deaths in the future. The agency does not enforce compliance with State or Federal occupational safety and health standards and does not determine fault or assign blame. Participation of fire departments and individuals in NIOSH investigations is voluntary. Under its program, NIOSH investigators interview persons with knowledge of the incident who agree to be interviewed and review available records to develop a description of the conditions and circumstances leading to the death(s). Interviewees are not asked to sign sworn statements and interviews are not recorded. The agency's reports do not name the victim, the fire department or those interviewed. The NIOSH report's summary of the conditions and circumstances surrounding the fatality is intended to provide context to the agency's recommendations and is not intended to be definitive for purposes of determining any claim or benefit.

For further information, visit the program website at www.cdc.gov/niosh/fire or call toll free 1-800-CDC-INFO (1-800-232-4636). 


\section{Death in the line of duty... Nysh}

A summary of a NIOSH fire fighter fatality investigation

April 7, 2015

\section{Major Suffers Sudden Cardiac Death After Annual Physical Ability Test - Kentucky}

\section{Introduction}

On October 30, 2014, a 60-year-old male Major in the fire service suffered sudden cardiac death a few hours after his annual PAT. The United States Fire Administration notified NIOSH of this fatality on November 3, 2014. NIOSH contacted the affected fire department on November 3, 2014, to obtain further information and on November 12, 2014, to initiate the investigation. On November 17, 2014, a safety and occupational health specialist from the NIOSH Fire Fighter Fatality Investigation Team traveled to Kentucky to conduct an on-site investigation of the incident.

During the investigation NIOSH personnel met and/or interviewed the following people:

- Fire chief

- Fire department administrative assistant

- Major's wife

During the site visit NIOSH personnel reviewed the following records:

- Fire department training records

- Fire department annual response report for 2013

- Fire department incident report

- Fire department medical records

- Primary care physician records

- Ambulance report

- Death certificate

- Autopsy report

\section{Investigation}

On October 30, 2014, at 0645 hours, the Major left his home for his annual fit-for-duty evaluation at the fire department contract physician's office. The fit-for-duty evaluation consisted of two parts: a medical evaluation and a PAT. From 0800 hours to 0900 hours, the Major completed the medical evaluation, which consisted of a medical examination, spirometry, a resting electrocardiogram (EKG), an audiogram, and a blood draw. The resting EKG showed nonspecific ST-T wave changes unchanged from previous years. The PAT, also conducted at the contract-physician's facility, consisted of 10 timed maneuvers over about 25 minutes; seven maneuvers were conducted in full turnout gear and pack weighing 25 pounds (Appendix A). The test evaluator noted the Major "did well with all tasks" and did not note any signs or symptoms of heart problems. 


\section{Major Suffers Sudden Cardiac Death After Annual Physical Ability Test - Kentucky}

The Major left the physician's office at about 1030 hours. On the way home, he called his wife on his cell phone and gave no indication of any medical problems. At 1059 hours, he stopped at an abandoned gas station and called 911. He discontinued the call after only a few seconds. When the 911 operator called him back, he stated that he did not need assistance. He then called a crew member to discuss a work project (1108 hours). The crew member noted that the Major did not sound well and questioned him. The Major stated that he had just completed his annual fit-for-duty exam and there was no problem.

The Major did not return home that evening. His family used the global positioning system in his cell phone to locate him at the gas station. They 911 called (2135 hours), and the local fire department and an ambulance were dispatched. When units arrived on the scene at 2142 hours (fire department) and 2155 hours (ambulance), the Major was found deceased (cold body and rigor mortis). The coroner was notified, and the Major was pronounced dead.

\section{Medical Findings}

The death certificate and the autopsy, completed by the county medical examiner, listed "hypertensive and atherosclerotic cardiovascular disease" as the cause of death with "obesity" as a contributing factor. The Major had moderate coronary artery disease, cardiomegaly, and left ventricular hypertrophy (LVH). See Appendix B for additional findings from the autopsy.

The Major had a history of the following pertinent medical problems:

Hypertension - diagnosed in 2010 and controlled with a blood pressure-lowering medication with no complications, although a stress echocardiogram in 2012 noted borderline concentric LVH.

Elevated low density lipoprotein cholesterol - diagnosed in 2012 but not prescribed a cholesterollowering medication.

Obesity - At his medical evaluation on the day of his death, the Major was 70 inches tall and weighed 243 pounds, giving him a body mass index of 34.9 kilograms per square meter [CDC 2014].

Fire Department Medical Evaluations. The Major's last EST, a stress echocardiogram, was performed in December 2013. He exercised for 8 minutes on the Bruce protocol (Stage 3) achieving 10 metabolic equivalents (METs). The test was stopped because he reached $94 \%$ of his maximum predicted heart rate. He reported no symptoms of angina. His left ventricle size, thickness, and function were normal with a left ventricular ejection fraction calculated at 53\%. He also had a normal blood pressure response to exercise. His stress EKG revealed a 1-mm ST depression and frequent premature ventricular contractions (PVCs). The ST segment depression of 1.0 to 2.0 millimeters was a consistent finding in prior ESTs as were the occasional/frequent PVCs. These findings were not thought to be ischemic because no defects were seen on nuclear EST scans in 2007 and 2010. The cardiologist summarized the stress echocardiogram as normal, and the Major was cleared for unrestricted duty. 


\section{Major Suffers Sudden Cardiac Death After Annual Physical Ability Test - Kentucky}

\section{Fire Department}

At the time of the NIOSH investigation, the fire department consisted of four fire stations with 74 uniformed personnel (17 career and 57 volunteer) serving 45,000 residents in a geographic area of 56 square miles. In 2013, the fire department responded to 910 calls including 643 fire calls and 267 medical calls.

\section{Employment, Membership, Training, and Experience}

The fire department requires career fire fighter applicants to be 18 years of age, have a valid state driver's license, possess a Kentucky fire fighter I certificate, complete an orientation class, pass a fire department medical evaluation to include a physical agility test (Appendix A), pass a background check, and complete an interview with the personnel office before being offered employment. Volunteer applicants must complete the same process but are placed into a 10-month training academy to be trained to the fire fighter I and II and hazardous materials operations levels. All applicants are probationary for 1 year. The Major was trained as a fire fighter I and II, apparatus operator, emergency medical technician, fire officer, fire service instructor, fire inspector, wildland fire fighter, hazardous materials technician, and in technical rescue. He had 15 years of fire fighting experience and served as the training bureau chief.

\section{Preplacement and Annual Medical Evaluations/Return to Work Medical Evaluations}

The fire department requires preplacement medical evaluations. The medical evaluations are performed by a fire department-contracted physician who makes a determination regarding medical clearance for fire fighting duties and forwards this decision to the fire department. Components of this evaluation include the following:

- Complete medical history

- Physical examination (including vital signs - height, weight, blood pressure, pulse, and respirations)

- Laboratory blood tests (complete blood count, comprehensive metabolic panel, and chemistry 19 panel)

- Vision test (acuity, color, peripheral fields, and depth perception)

- Audiogram

- Urinalysis

- Urine drug screen

- Tuberculosis skin test

- Chest x-ray (baseline)

- Pulmonary function test

- EST

- Flu vaccine (voluntary)

- Hepatitis-B antibody/series/booster

- Self-contained breathing apparatus respirator clearance 


\section{Major Suffers Sudden Cardiac Death After Annual Physical Ability Test - Kentucky}

Annual medical evaluations are also required. The components are the same except the EST is given every 3 years for members age 35 and older and every year for members age 50 and older. The Major did not have an EST during his 2014 evaluation because his 2013 results were normal. If a condition is discovered that affects a member's ability to perform his or her duties, the member is placed off-duty until the condition is resolved. When a member is injured on duty, a medical clearance is required by the contract physician, who forwards a determination for return to duty to the fire department. If the member is ill and misses more than two consecutive shifts, a medical clearance is required by the primary care physician, who forwards a determination for return to duty to the fire department.

\section{Fitness/Wellness Programs}

The fire department has a voluntary wellness/fitness program, and exercise equipment is available in all fire stations. An annual job performance PAT is required for all members (Appendix A). The Major regularly participated in physical fitness activities by walking in the evening; he demonstrated fair aerobic capacity (10 METs) during his 2013 EST.

\section{DISCUSSION}

\section{Sudden Cardiac Events}

In the United States, atherosclerotic CHD is the most common risk factor for cardiac arrest and sudden cardiac death [Meyerburg and Castellanos 2008]. Risk factors for its development include three nonmodifiable risk factors (age older than 45, male gender, family history of coronary artery disease [CAD]) and five modifiable risk factors (smoking, high blood pressure, high blood cholesterol, obesity/physical inactivity, and diabetes) [NHLBI 2014a; AHA 2015]. The Major had two known modifiable CHD risk factors: high blood pressure and obesity. His autopsy showed moderate CHD and complications of longstanding hypertension (LVH, cardiomegaly, and nephrosclerosis).

The narrowing of the coronary arteries by atherosclerotic plaques occurs over many years, typically decades [Libby 2013]. However, the growth of these plaques probably occurs in a nonlinear, often abrupt fashion. Heart attacks typically occur with the sudden development of complete blockage (occlusion) in one or more coronary arteries that have not developed a collateral blood supply. This sudden blockage is primarily due to blood clots (thrombosis) forming on ruptured atherosclerotic plaques [Libby 2013]. Establishing a recent heart attack requires any of the following: elevated cardiac enzymes, coronary artery thrombus, or characteristic EKG changes. In this case, the Major's cardiac enzymes were not tested, no thrombus was revealed at autopsy, and he did not have a heart rhythm on which to conduct an EKG. Given that heart attacks can occur without a coronary thrombus, it is possible that the Major had a heart attack [Davies 1992; Farb et al. 1995]. However, his lack of angina during the PAT makes this less likely.

\section{Primary Arrhythmia}

It is likely that the Major's sudden cardiac death was the result of a primary cardiac arrhythmia associated with his underlying CHD, cardiomegaly, and LVH. Risk factors for arrhythmias include cardiac disease, heart attack, sleep apnea, dietary supplements, smoking, alcohol, drug abuse, 


\section{Major Suffers Sudden Cardiac Death After Annual Physical Ability Test - Kentucky}

medications, diabetes, and hyperthyroidism [AHA 2014; Mayo Clinic 2014]. The Major had several types of undiagnosed heart disease (CHD, cardiomegaly, $\mathrm{LVH})$, and probably had sleep apnea.

\section{Physiological Stress of Firefighting}

In addition to medical conditions, sudden cardiac death has been linked to heavy physical exertion [Albert et al. 2000; Patterson et al. 2013]. Among fire fighters, sudden cardiac events have been associated with/triggered by alarm response, fire suppression, and heavy exertion during training (including physical fitness training) [Kales et al. 2003; Kales et al. 2007; NIOSH 2007]. The Major's activities performing the PAT would have expended about 12 metabolic equivalents (METs), which is considered heavy physical activity [Gledhill and Jamnik 1992; Ainsworth et al. 2011]. The arrhythmia that likely caused the Major's sudden cardiac death may have been triggered by the physical exertion associated with his PAT.

During the EST, the Major was noted to have frequent PVCs. When PVCs are elicited during exercise testing, even in individuals without known structural heart problems, these individuals appear to be at increased risk of sudden cardiac events [Frolkis et al. 2003; Jouven et al. 2000; Zipes et al. 2006]. According to NFPA, medical clearance for fire fighters with PVCs should involve a reduction in the number of PVCs with increasing levels of exercise up to 12 METs [NFPA 2013]. In this case, the Major's PVCs increased with exercise. It is unclear if this finding, by itself, should have resulted in work restrictions for the Major.

\section{Occupational Medical Standards for Structural Fire Fighters}

To reduce the risk of sudden cardiac arrest or other incapacitating medical conditions among fire fighters, the National Fire Protection Association developed NFPA 1582, Standard on Comprehensive Occupational Medical Program for Fire Departments [NFPA 2013]. This voluntary industry standard provides the components of a preplacement and annual medical evaluation and medical fitness for duty criteria. Despite annual EST for the past 6 years (one non-imaging, two nuclear, and three echocardiograms), the Major's underlying CHD was not identified until after this incident. This is probably due to the limitation of the imaging ESTs. Imaging ESTs, either nuclear or echocardiograms, have sensitivities and specificities of approximately 95\% [Gibbons et al. 2002; Grundy 2003]. For nonmaximal imaging EST, the sensitivities and specificities are lower [Gibbons et al. 2002]. Apparently, the Major was one of the few whose CHD risk for sudden cardiac death was not identified by the ESTs.

Recommendations on whether to screen asymptomatic individuals for CHD with EST are varied. The following paragraphs summarize the positions of widely recognized organizations on this topic.

\section{NFPA}

NFPA 1582, a voluntary industry standard, recommends an EST performed "as clinically indicated by history or symptoms" and refers the reader to Appendix A [NFPA 2013]. Items in Appendix A are not standard requirements, but are provided for "informational purposes only." Appendix A recommends using submaximal ( $85 \%$ of predicted heart rate) EST as a screening tool to evaluate a fire fighter's 


\section{Major Suffers Sudden Cardiac Death After Annual Physical Ability Test - Kentucky}

aerobic capacity. Maximal (i.e., symptom-limiting) EST with imaging should be used for fire fighters with the following conditions:

- abnormal screening submaximal tests

- cardiac symptoms

- known CAD

- one or more risk factors for CAD (in men older than 45 and women older than 55); risk factors are defined as hypercholesterolemia (total cholesterol greater than 240 milligrams per deciliter), hypertension (diastolic blood pressure greater than $90 \mathrm{~mm}$ of mercury), smoking, diabetes mellitus, or family history of premature CAD (heart attack or sudden cardiac death in a first-degree relative less than 60 years old)

- Framingham Risk Score (FRS) > 10\%

Given the Major's age, treated hypertension, and Framingham Risk Score of 11\%, NFPA 1582 would have recommended a symptom-limiting EST.

\section{American College of Cardiology/American Heart Association (ACC/AHA)}

The ACC/AHA has also published exercise testing guidelines [Gibbons et al. 2002]. The ACC/AHA guideline states that the evidence to conduct stress tests in asymptomatic individuals is "less well established" (Class IIb) for the following groups:

- persons with multiple risk factors (defined similarly to those listed by the NFPA)

- asymptomatic men older than 45 years and women older than 55 years:

o who are sedentary and plan to start vigorous exercise

o who are involved in occupations in which impairment might jeopardize public safety (e.g., fire fighters)

o who are at high risk for coronary artery disease due to other diseases (e.g., peripheral vascular disease and chronic renal failure)

Given the Major's public safety position, the ACC/AHA criteria suggest an EST would have been appropriate for the Major.

\section{U.S. Department of Transportation}

The U.S. Department of Transportation provides guidance for those seeking medical certification for a commercial driver's license. An expert medical panel recommended exercise tolerance tests (stress tests) for asymptomatic "high risk" drivers [Blumenthal et al. 2007]. The panel defines high risk drivers as those with any of the following:

- diabetes mellitus

- peripheral vascular disease

- age 45 and above with multiple risk factors for CHD

- FRS predicting a 20\% CHD event risk over the next 10 years 


\section{Major Suffers Sudden Cardiac Death After Annual Physical Ability Test - Kentucky}

Although the Major's FRS was 11\%, he was over age 45 with multiple risk factors for CHD. Therefore, the U.S. Department of Transportation would have recommended an EST for a commercial truck driver with a similar profile [NHLBI 2014b].

\section{U.S. Preventive Services Task Force (USPSTF)}

The U.S. Preventive Services Task Force (USPSTF) does not recommend stress tests for asymptomatic individuals at low risk for CHD events. For individuals at increased risk for CHD events, the USPSTF found "insufficient evidence to recommend for or against routine screening with EKG, exercise tolerance test, or electron beam computerized tomography scanning...." Rather, they recommend the diagnosis and treatment of modifiable risk factors (hypertension, high cholesterol, smoking, and diabetes) [USPSTF 2004]. The USPSTF does note that "For people in certain occupations, such as pilots, and heavy equipment operators (for whom sudden incapacitation or sudden death may endanger the safety of others), consideration other than the health benefit to the individual patient may influence the decision to screen for coronary heart disease."

\section{Recommendations}

Recommendation \#1: Perform symptom-limiting ESTs on fire fighters at increased risk for CHD and sudden cardiac events.

Discussion: We applaud the fire department for including EST in fire fighter annual medical evaluations. An EST was indicated in this case because the Major was $>45$ years old and had a FRS of $11 \%$ putting him at increased risk of a sudden cardiac event [NHLBI 2014a, AHA 2015]. However, the contractor is not using symptom-limiting tests as recommended by AHA/ACC and the NFPA [Gibbons 2002; NFPA 2013]. A symptom-limiting EST may have identified his underlying CHD, possibly leading to further evaluation and treatment.

\section{Recommendation \#2: Perform ESTs only on fire fighters at increased risk for CHD and sudden cardiac events.}

Discussion: Again, we applaud the fire department for conducting ESTs. Currently the fire department is using age as the sole determinant to initiate ESTs. While age is a very important factor in sudden cardiac events, it is not the sole factor. Sex and CHD risk are other important factors to consider. NIOSH recommends the fire department review the AHA/ACC and/or the NFPA 1582 document about when to initiate ESTs, and their frequency [IAFF, IAFC 2008; Gibbons et al. 2002; NFPA 2013].

Recommendation \#3: Ensure that fire fighters are cleared for duty by a physician knowledgeable about the physical demands of fire fighting, the personal protective equipment used by fire fighters, and the components of NFPA 1582.

Discussion: Guidance regarding medical evaluations and examinations for structural fire fighters can be found in NFPA 1582 and in the IAFF/IAFC Fire Service Joint Labor Management Wellness/Fitness 


\section{Major Suffers Sudden Cardiac Death After Annual Physical Ability Test - Kentucky}

Initiative [IAFF, IAFC 2008; NFPA 2013a]. The fire department has a contracted physician who is responsible for guiding, directing, and advising the members with regard to their health, fitness, and suitability for duty. However, the fire department allows personal physicians to clear a member who is ill and misses more than two consecutive shifts. NIOSH recommends that the fire departmentcontracted physician also review and approve these medical clearances for member illnesses by personal physicians.

\section{Recommendation \#4: Phase in a mandatory comprehensive wellness and fitness program for fire fighters.}

Discussion: Guidance for fire department wellness/fitness programs to reduce risk factors for cardiovascular disease and improve cardiovascular capacity is found in NFPA 1583, Standard on Health-Related Fitness Programs for Fire Fighters, the IAFF/IAFC Fire Service Joint Labor Management Wellness/Fitness Initiative, and in Firefighter Fitness: A Health and Wellness Guide [IAFF, IAFC 2008; NFPA 2008; Schneider 2010]. Worksite health promotion programs have been shown to be cost effective by increasing productivity, reducing absenteeism, and reducing the number of work-related injuries and lost work days [Pelletier 2009; Baicker et al. 2010]. Fire service health promotion programs have been shown to reduce CHD risk factors and improve fitness levels, with mandatory programs showing the most benefit [Dempsey et al. 2002; Womack et al. 2005; Blevins et al. 2006; Poston et al. 2013]. A study conducted by the Oregon Health and Science University reported a savings of more than $\$ 1$ million for each of four large fire departments implementing the IAFF/IAFC wellness/fitness program compared to four large fire departments not implementing a program. These savings were primarily due to a reduction of occupational injury/illness claims with additional savings expected from reduced future nonoccupational healthcare costs [Kuehl et al. 2013]. At the time of our investigation, the fire department had a voluntary wellness/fitness program. NIOSH recommends a formal, mandatory wellness/fitness program to ensure all members receive the benefits of a health promotion program.

Additionally, NFPA 1582 recommends counselling for members whose aerobic capacity is below 12 METs and recommends a prescribed aerobic fitness program and potential work restriction for aerobic capacity at or below 8 METs [NFPA 2013a].

\section{References}

AHA [2014]. Understand your risk for arrhythmia. Dallas, TX: American Heart Association. [http://www.heart.org/HEARTORG/Conditions/Arrhythmia/UnderstandYourRiskforArrhythmia/Unde rstand-Your-Risk-for-Arrhythmia_UCM_002024_Article.jsp]. Date accessed: March 2015.

AHA (American Heart Association) [2015]. Understand your risk of heart attack. Dallas, TX: American Heart Association.

[http://www.heart.org/HEARTORG/Conditions/HeartAttack/UnderstandYourRiskofHeartAttack/Unde rstand-Your-Risk-of-Heart-Attack_UCM_002040_Article.jsp]. Date accessed: March 2015. 


\section{Major Suffers Sudden Cardiac Death After Annual Physical Ability Test - Kentucky}

Ainsworth BE, Haskell WL, Herrmann SD, Meckes N, Bassett DR Jr, Tudor-Locke C, Greer JL, Vezina J, Whitt-Glover MC, Leon AS [2011]. Compendium of physical activities: a second update of codes and MET values. Med Sci Sports Exerc 43(8):1575-1581.

Albert CM, Mittleman MA, Chae CU, Lee IM, Hennekens CH, Manson JE [2000]. Triggering of sudden death from cardiac causes by vigorous exertion. N Engl J Med 343(19):1355-1361.

Baicker K, Cutler D, Song Z [2010]. Workplace wellness programs can generate savings. Health Affairs 29(2):1-8.

Blevins JS, Bounds R, Armstrong E, Coast JR [2006]. Health and fitness programming for fire fighters: does it produce results? Med Sci Sports Exerc 38(5):S454.

Blumenthal RS, Epstein AE, Kerber RE [2007]. Expert panel recommendations. Cardiovascular disease and commercial motor vehicle driver safety.

[http://www.mrb.fmcsa.dot.gov/documents/CVD_Commentary.pdf]. Date accessed: March 2015.

CDC (Centers for Disease Control and Prevention) [2014]. Assessing your weight.

[http://www.cdc.gov/healthyweight/assessing/index.html]. Date accessed: March 2015.

Davies MJ [1992]. Anatomic features in victims of sudden coronary death. Coronary artery pathology. Circulation 85[Suppl I]:I-19-24.

Dempsey WL, Stevens SR, Snell CR [2002]. Changes in physical performance and medical measures following a mandatory firefighter wellness program. Med Sci Sports Exerc 34(5):S258.

Farb A, Tang AL, Burke AP, Sessums L, Liang Y, Virmani R [1995]. Sudden coronary death: frequency of active lesions, inactive coronary lesions, and myocardial infarction. Circulation 92(7):1701-1709.

Frolkis JP, Pothier CE, Blackstone EH, Lauer MS [2003]. Frequent ventricular ectopy after exercise as a predictor of death. N Engl J Med 348(9):781-790.

Gibbons RJ, Balady GJ, Bricker JT, Chaitman BR, Fletcher GF, Froelicher VF, Mark DB, McCallister BD, Mooss AN, O’Reilly MG, Winters WL Jr., Antman EM, Alpert JS, Faxon DP, Fuster V, Gregoratos G, Hiratzka LF, Jacobs AK, Russell RO, Smith SC Jr [2002]. ACC/AHA 2002 guideline update for exercise testing: a report of the American College of Cardiology/ American Heart Association Task Force on Practice Guidelines. Circulation 106(14):1883-1892.

Gledhill N, Jamnik VK [1992]. Characterization of the physical demands of firefighting. Can J Sport Sci 17(3):207-213.

Grundy SM [2003]. Atherosclerosis imaging for risk assessment and primary prevention of cardiovascular disease. Prog Cardiovasc Dis 46(2):115-212. 


\section{Major Suffers Sudden Cardiac Death After Annual Physical Ability Test - Kentucky}

IAFF, IAFC [2008]. The fire service joint labor management wellness/fitness initiative. 3rd ed. Washington, DC: International Association of Fire Fighters, International Association of Fire Chiefs.

Jouven X, Zureik M, Desnos M, Courbon D, Ducimetiere P [2000]. Long-term outcome in asymptomatic men with exercise-induced premature ventricular depolarizations. N Engl J Med 343(12):826-833.

Kales SN, Soteriades ES, Christoudias SG, Christiani DC [2003]. Firefighters and on-duty deaths from coronary heart disease: a case control study. Environ Health: a global access science source. 2:14. [http://www.ehjournal.net/content/2/1/14]. Date accessed: March 2015.

Kales SN, Soteriades ES, Christophi CA, Christiani DC [2007]. Emergency duties and deaths from heart disease among fire fighters in the United States. N Engl J Med 356(12):1207-1215.

Kuehl KS, Elliot DL, Goldberg L, Moe EL, Perrier E, Smith J [2013]. Economic benefit of the PHLAME wellness programme on firefighter injury. Occ Med 63(3):203-209.

Libby P [2013]. Mechanisms of acute coronary syndromes and their implications for therapy. N Engl J Med 368(21):2004-2013.

Mayo Clinic [2014]. Heart arrhythmias. [http://www.mayoclinic.com/health/heartarrhythmias/DS00290/METHOD=print\&DSECTION=all]. Date accessed: March 2015.

Meyerburg RJ, Castellanos A [2008]. Cardiovascular collapse, cardiac arrest, and sudden cardiac death. In: Fauci AS, Braunwald E, Kasper DL, Hauser SL, Longo DL, Jameson JL, Loscalzo J, eds. Harrison's principles of internal medicine. 17th ed. New York: McGraw-Hill, pp. 1707-1713.

NFPA [2008]. Standard on health-related fitness programs for fire fighters. Quincy, MA: National Fire Protection Association. NFPA 1583.

NFPA [2013]. Standard on comprehensive occupational medical program for fire departments. Quincy, MA: National Fire Protection Association. NFPA 1582.

NHLBI [2014a]. Who is at risk for coronary artery disease? National Heart, Lung, and Blood Institute. [http://www.nhlbi.nih.gov/health/health-topics/topics/cad/atrisk.html]. Date accessed: March 2015.

NHLBI [2014b]. Risk assessment tool for estimating your 10-year risk of having a heart attack. National Heart, Lung, and Blood Institute. [http://cvdrisk.nhlbi.nih.gov/calculator.asp]. Date accessed: March 2015.

NIOSH [2007]. NIOSH alert: preventing fire fighter fatalities due to heart attacks and other sudden cardiovascular events. Cincinnati, OH: U.S. Department of Health and Human Services, Centers for Disease Control and Prevention, National Institute for Occupational Safety and Health, DHHS 


\section{Major Suffers Sudden Cardiac Death After Annual Physical Ability Test - Kentucky}

(NIOSH) Publication No. 2007-133. [http://www.cdc.gov/niosh/docs/2007-133/]. Date accessed: March 2015.

Patterson PD, Suyama J, Reis SE, Weaver MD, Hostler D [2013]. What does it cost to prevent on-duty firefighter cardiac events? A content valid method for calculating costs. Adv Prev Med Epub 2013.

Pelletier KR [2009]. A review and analysis of the clinical and cost-effectiveness studies of comprehensive health promotion and disease management programs at the worksite: update VII 20042008. J Occup Environ Med 51(7):822-837.

Poston WSC, Haddock CK, Jahnke SA, Jitnarin N, Day RS [2013]. An examination of the benefits of health promotion programs for the national fire service. BMC Pub Health 13(1):805-819.

Schneider EL [2010]. Firefighter fitness: a health and wellness guide. New York: Nova Science Publishers.

USPSTF [2004]. U.S. Prevention Services Task Force. Screening for coronary heart disease: Recommendation Statement. Ann Intern Med 140(7):569-572.

Womack JW, Humbarger CD, Green JS, Crouse SF [2005]. Coronary artery disease risk factors in firefighters: effectiveness of a one-year voluntary health and wellness program. Med Sci Sports Exerc 37(5):S385.

Zipes DP, Camm AJ, Borggrefe M, Buxton AE, Chaitman B, Fromer M, Gregoratos G, Klein G, Moss AJ, Meyerburg RJ, Priori SG, Quinones MA, Roden DM, Silka MJ, Tracy C [2006]. ACC/AHA/ESC 2006 guidelines for management of patients with ventricular arrhythmias and the prevention of sudden cardiac death: a report of the American College of Cardiology/American Heart Association Task Force and the European Society of Cardiology Committee for Practice Guidelines (Writing Committee to Develop Guidelines for Management of Patients With Ventricular Arrhythmias and the Prevention of Sudden Cardiac Death). Circulation 114(10):e385-e484.

\section{Investigator Information}

This incident was investigated by the NIOSH Fire Fighter Fatality Investigation and Prevention Program, Cardiovascular Disease Component in Cincinnati, Ohio. Mr. Tommy Baldwin (MS) led the investigation and co-authored the report. Mr. Baldwin is a Safety and Occupational Health Specialist, a National Association of Fire Investigators (NAFI) Certified Fire and Explosion Investigator, an International Fire Service Accreditation Congress (IFSAC) Certified Fire Officer I, and a former Fire Chief and Emergency Medical Technician. Dr. Thomas Hales (MD, MPH) provided medical consultation and co-authored the report. Dr. Hales is a member of the NFPA Technical Committee on Occupational Safety and Health, and Vice-Chair of the Public Safety Medicine Section of the American College of Occupational and Environmental Medicine (ACOEM). 


\section{Major Suffers Sudden Cardiac Death After Annual Physical Ability Test - Kentucky}

\section{Disclaimer}

Mention of any company or product does not constitute endorsement by the National Institute for Occupational Safety and Health (NIOSH). In addition, citations to Web sites external to NIOSH do not constitute NIOSH endorsement of the sponsoring organizations or their programs or products.

Furthermore, NIOSH is not responsible for the content of these Web sites. 


\section{Major Suffers Sudden Cardiac Death After Annual Physical Ability Test - Kentucky}

\section{Appendix A Annual Physical Ability Test}

1. Functional Spinal and Extremity Motion: Functional upper and lower extremity motion for reaching and squatting while completing job tasks.

2. Exert Sufficient Force to Turn Steering Wheel: Tested as turning wheel with 50 foot/pounds force repetitively clockwise/counterclockwise for 3 minutes.

3. Carry Tools Up Ladder: Wearing full gear and pack, climb to fifth rung carrying a 20-pound box up ladder four times in 2 minutes.

4. Lift Heavy Equipment for Use to Fight Fire: Wearing full gear and pack, lift 70 pounds floor to waist five times in 5 minutes.

5. Carry Heavy Equipment: Wearing full gear and pack, carry a 70-pound box for a distance of 20 feet five times in 5 minutes.

6. Simulate Using Tools Overhead for Removing Drywall: Wearing full gear and pack, use the tool overhead at a torque of 180-inch pounds; pull for 2 minutes and then pull for 2 minutes at the rate of at least 20 repetitions per minute.

7. Simulate Patient Transfers Stretcher to Gurney. Transfer staff member table to table and up/down the table for positioning. Each transfer must be completed two times.

8. Simulate Advancing the Fire Hose: Wearing full gear and pack, pull the 150-pound weighted sled with a strap a distance of 40 feet four times in 2 minutes.

9. Simulate Rescue of Person from Building: Wearing full gear and pack, walk backwards while dragging a blanket with the equivalent of a 200-pound adult person on it. Drag the blanket 55 feet in 1 minute.

10. Simulate Lifting Ladder off the Fire Truck: Wearing full gear and pack, the candidate is tested by lifting the 12 -foot ladder off the 60 -inch shelf. Perform three repetitions in 1 minute.

The candidate either demonstrates all or some of the essential functions of the job as tested. If "SOME" is identified, the evaluator must elaborate. 


\section{Major Suffers Sudden Cardiac Death After Annual Physical Ability Test - Kentucky}

\section{Appendix B Autopsy Findings}

- Coronary artery atherosclerosis

$\circ 75 \%$ focal narrowing in the mid and distal left anterior descending coronary artery

○ $50 \%$ focal narrowing of both the left circumflex coronary artery and the right coronary artery

- Microscopic evidence of myocyte hypertrophy, focal slight interstitial fibrosis and focal fatty infiltration of the myocardium

- Hypertensive heart disease

$\circ$ Cardiomegaly (heart weighed 550 grams [g]; predicted normal weight is $410 \mathrm{~g}$ [ranges between $311 \mathrm{~g}$ and $541 \mathrm{~g}$ as a function of sex, age, and body weight]) [Silver and Silver 2001

○ Biventricular hypertrophy

- Left ventricle and interventricular septum thickened $(1.8$ centimeter $[\mathrm{cm}]$ and $2.0 \mathrm{~cm}$ respectively)

○ Normal at autopsy is $0.76-0.88 \mathrm{~cm}$ [Colucci and Braunwald 1997]

○ Normal by echocardiographic measurement is $0.6-1.0 \mathrm{~cm}$ [Connolly and Oh 2012]

- Right ventricle thickened $(0.5 \mathrm{~cm})$

$\circ$ Normal at autopsy is $0.2-0.7 \mathrm{~cm}$ with an average of $0.35-0.39 \mathrm{~cm}$ [Hutchins and Anaya 1973; Murphy et al. 1988]

○ Normal by echocardiography $0.7-2.3 \mathrm{~cm}$ [Armstrong and Feigenbaum 2001]

○ Arterial and arteriolar nephrosclerosis

- No evidence of thrombus (blood clot)

- Normal cardiac valves

- No evidence of a pulmonary embolus (blood clot in the lung arteries)

- Positive urine drug test for morphine (53 nanograms per milliliter). During interviews with the fire chief and the family, NIOSH learned that the Major had knee surgery in August 2014 and was prescribed a pain medication to take as needed.

\section{REFERENCES}

Armstrong WF, Feigenbaum H [2001]. Echocardiography. In: Braunwald E, Zipes DP, Libby P, eds. Heart disease: a text of cardiovascular medicine. 6th ed. Vol. 1. Philadelphia, PA: W.B. Saunders Company, p. 167.

Colucci WS, Braunwald E [1997]. Pathophysiology of heart failure. In: Braunwald, ed. Heart disease. 5th ed. Philadelphia, PA: W.B. Saunders Company, p. 401.

Connolly HM, Oh JK [2012]. Echocardiography. In: Bonow RO, Mann DL, Zipes DP, Libby P, Braunwald E, eds. Heart disease: a text of cardiovascular medicine. 9th ed. Vol. 1. Philadelphia, PA: Elsevier Saunders, p. 216. 


\section{Major Suffers Sudden Cardiac Death After Annual Physical Ability Test - Kentucky}

Hutchins GM, Anaya OA [1973]. Measurements of cardiac size, chamber volumes and valve orifices at autopsy. Johns Hopkins Med J 133(2):96-106.

Murphy ML, White HJ, Meade J, Straub KD [1988]. The relationship between hypertrophy and dilatation in the postmortem heart. Clin Cardiol 11(5):297-302.

Silver MM, Silver MD [2001]. Examination of the heart and of cardiovascular specimens in surgical pathology. In: Silver MD, Gotlieb AI, Schoen FJ, eds. Cardiovascular pathology. 3rd ed. Philadelphia, PA: Churchill Livingstone, pp. 8-9. 